\title{
Electrified methane reforming: A compact approach to greener industrial hydrogen production
}

Wismann, Sebastian Thor; Engbæk, Jakob S.; Vendelbo, Søren Bastholm; Bendixen, Flemming B.; Eriksen, Winnie L.; Aasberg-Petersen, Kim; Frandsen, Cathrine; Chorkendorff, Ib; Mortensen, Peter Mølgaard

Published in:

Science

Link to article, DOI:

10.1126/science.aaw8775

Publication date:

2019

Document Version

Peer reviewed version

Link back to DTU Orbit

Citation (APA):

Wismann, S. T., Engbæk, J. S., Vendelbo, S. B., Bendixen, F. B., Eriksen, W. L., Aasberg-Petersen, K., Frandsen, C., Chorkendorff, I., \& Mortensen, P. M. (2019). Electrified methane reforming: A compact approach to greener industrial hydrogen production. Science, 364(6442), 756-759.

https://doi.org/10.1126/science.aaw8775

\section{General rights}

Copyright and moral rights for the publications made accessible in the public portal are retained by the authors and/or other copyright owners and it is a condition of accessing publications that users recognise and abide by the legal requirements associated with these rights.

- Users may download and print one copy of any publication from the public portal for the purpose of private study or research.

- You may not further distribute the material or use it for any profit-making activity or commercial gain

- You may freely distribute the URL identifying the publication in the public portal 


\section{Title: Electrified methane reforming - A compact approach to greener industrial hydrogen production}

Authors: Sebastian T. Wismann ${ }^{1}$, Jakob S. Engbæk ${ }^{2}$ S $\varnothing$ ren B. Vendelboe ${ }^{2}$, Flemming B. Bendixen ${ }^{3}$, Winnie L. Eriksen ${ }^{4}$, Kim Aasberg-Petersen ${ }^{4}$, Cathrine Frandsen ${ }^{1}$, Ib Chorkendorff ${ }^{1 *}$, Peter M. Mortensen ${ }^{4 *}$

Affiliations:

${ }^{1}$ DTU Physics, Technical University of Denmark, 2800 Kongens Lyngby, Denmark. ${ }^{2}$ Danish

Technological Institute, 2630 Tåstrup, Denmark. ${ }^{3}$ Sintex A/S, 9500 Hobro, Denmark. ${ }^{4}$ Haldor Topsoe

10 A/S, 2800 Kongens Lyngby, Denmark.

*Corresponding author. Email: ibchork@fysik.dtu.dk; pmor@topsoe.com

Abstract: Electrification of conventionally fired chemical reactors has the potential to reduce

$\mathrm{CO}_{2}$ emissions, and provide flexible and compact heat generation. Here, we show a disruptive

approach to a fundamental process by integrating an electrically heated catalytic structure

15

directly into a steam-methane reforming (SMR) reactor for hydrogen production. Intimate

contact between the electric heat source and the reaction site drives the reaction close to thermal

equilibrium, increases catalyst utilization, and limits unwanted byproduct formation. The

integrated design with small characteristic length scales allows compact reactor designs,

potentially 100 times smaller than current reformer platforms. Electrification of SMR offers a

strong platform for new reactor design, scale, and implementation opportunities. Implemented on

a global scale this correspond to a reduction of nearly $1 \%$ of all $\mathrm{CO}_{2}$ emissions.

One Sentence Summary: Extremely compact electrified reactor for greener hydrogen production by steam-methane reforming at industrial scale. 
Main Text: Synthesis of important chemicals like hydrogen and ammonia has a significant $\mathrm{CO}_{2}$ footprint as the heating of the processes often rely on combustion of hydrocarbons. One of the largest endothermic processes is the production of hydrogen by steam-methane reforming, which accounts for ca. $50 \%$ of the global hydrogen supply, but also estimated $3 \%$ of global $\mathrm{CO}_{2}$ emissions $(1,2)$. In the strongly endothermic reaction, natural gas reacts with steam according to:

$$
\begin{gathered}
\mathrm{CH}_{4}+\mathrm{H}_{2} \mathrm{O} \rightleftharpoons \mathrm{CO}+3 \mathrm{H}_{2} \quad\left(\Delta \mathrm{H}_{\mathrm{r}}^{\circ}=+206 \mathrm{~kJ} / \mathrm{mol}\right) \\
\mathrm{CO}+\mathrm{H}_{2} \mathrm{O} \rightleftharpoons \mathrm{CO}_{2}+\mathrm{H}_{2} \quad\left(\Delta \mathrm{H}_{\mathrm{r}}^{\circ}=-41 \mathrm{~kJ} / \mathrm{mol}\right)
\end{gathered}
$$

Heat is typically supplied to the reaction by combustion of a mixture of natural gas and potential off-gasses from the synthesis. In total, conventional SMR produces 6.6-9.3 tons $\mathrm{CO}_{2}$ per ton of $\mathrm{H}_{2}$, of which $17-41 \%$ is the direct product of hydrocarbon combustion $(2,3)$.

Today, a large-scale industrial SMR reformer consists of an array of more than hundred 10-14 m long tubular reactors in a large furnace, with gas burners positioned for an optimal distribution of heat among the reactor tubes (4-6). The combustion must occur significantly above the reaction temperature to generate the necessary inward heat flux, as illustrated by the temperature profile in Figure $1 \mathrm{~A}(5,7)$. Due to limited thermal conductivity across the SMR catalyst and reactor walls, transporting the necessary heat to drive the reaction is a natural limitation (Fig. 1A), and typically less than $2 \%$ of the furnace volume contains catalyst $(5,8)$. Intrinsic catalytic activity is typically not a limiting factor for industrial reforming (9). Instead, the low thermal conductivity combined with a strongly endothermic reaction creates steep temperature gradients across the catalyst, leading to poor catalyst utilization and increasing risk of detrimental carbon formation $(10-12)$.

20 For decades, thermal conductivity of SMR has been subject to research. Efforts include catalyst with higher thermal conductivity (13), low-temperature SMR by shifting the equilibrium (14- 
17), shorter characteristic length scales through $\mu$-reactors $(18,19)$, room temperature reaction using plasma (20), or direct heating of magnetic catalysts by induction (21). Alternatively, electrical heating of an integrated catalytically coated heating element, enables reactor temperatures exceeding what is feasible in conventional reactors (22), and allows significantly improved temporal response, pushing start-up times to within minutes (23). However, despite decades of research, no alternatives with lower $\mathrm{CO}_{2}$ emissions have been implemented at industrial scale.

This work describes a high-performing, fully electrically-driven reformer, based on direct resistive (Ohmic) heating (Fig. 1B), scalable to industrial conditions and capacities. The intimate contact between the electric heat source and the catalyst enables energy supplied directly to the catalytic sites, removing thermal limitations and providing well-defined control of the reaction front. Electrification removes the fired section, substantially reducing reactor volume, $\mathrm{CO}_{2}$ emissions, and waste-heat streams. This provides a disruptive advantage to existing industrial reformers, enabling production of greener hydrogen for large scale synthesis of indispensable chemicals, such as methanol, ammonia, and biofuels $(24,25)$. 
A Conventional technology

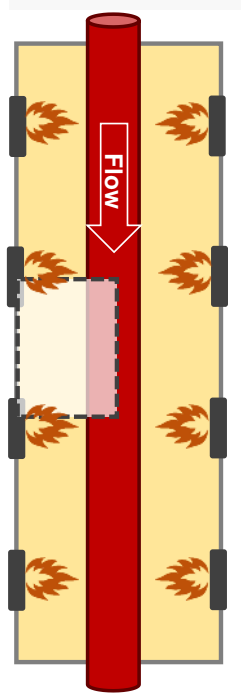

B

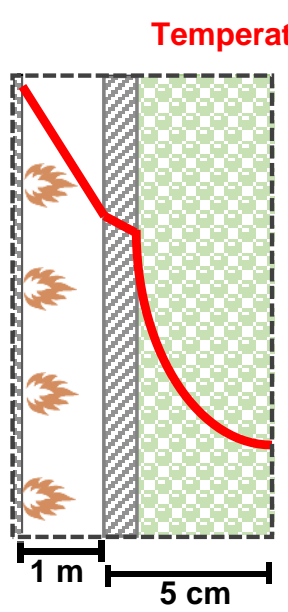

Characteristic length scales
Electric heating

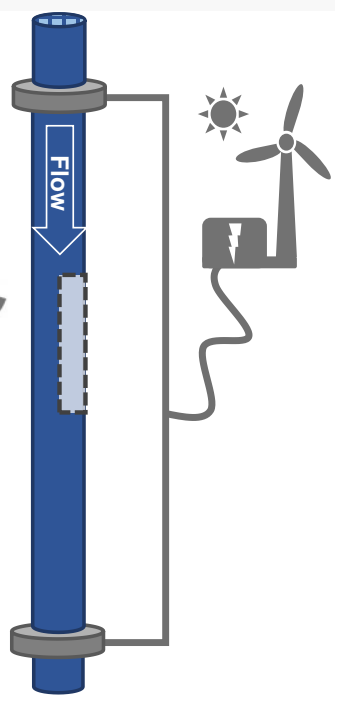

Fig. 1. Heating principles A) Conventional fired reactor. B) Electric resistance-heated reactor. Characteristic radial length scales and temperature profiles are shown across heat source, reactor wall (grey) and catalyst material (green). In $B$, heat source and reactor wall are one. Illustrations are not to scale.

For this work, we prepared a lab-scale reactor based on a FeCrAl-alloy tube, chosen for its temperature-independent electrical resistance, coated with a ca. $130 \mu \mathrm{m}$ nickel-impregnated washcoat on the interior of the tube (26). Copper sockets were mounted at opposite ends of the external surface of the reactor tube, and resistive heating was accomplished by applying an AC current along the tube (Fig. 2A). This allowed a direct heat supply to the catalytic washcoat (Fig. 2B). A section of the coat was removed in both ends of the reactor to obtain a quantified length of the catalyst (Fig. 2C), and to prevent reverse reaction towards the outlet. However, a thin residual layer of catalytically active coat $(<5 \mu \mathrm{m})$ was present at the lower section of the reactor (Fig. S1) due the impregnation method of the material. Temperature profiles were measured 
using multiple thermocouples spot-welded to the tube (Fig. 2D). The entire reactor was encapsulated in high-temperature insulation material.

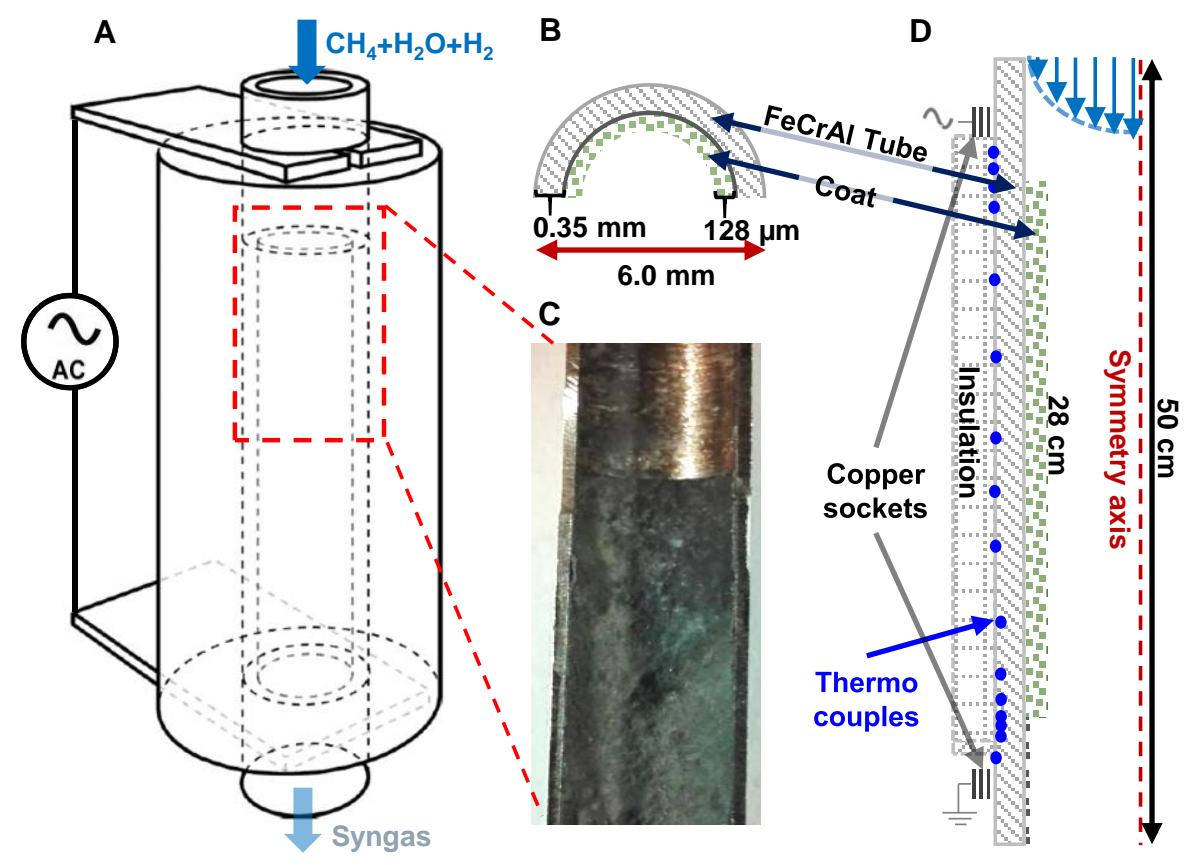

Fig. 2. Lab-scale resistance-heated reformer A) Resistance-heated reactor setup. The illustration is not to scale. (B) Cross-sectional illustration of the reactor in the coated region. (C) Axial cross-section of the reactor after experiments, showing the well-defined edge of the coat. (D) Axisymmetrical reactor cross section, outlining the most relevant domains and thermocouple positions. before entering the reactor. The experiments were operated 50 mbar above ambient, as the reactor was not prepared for pressure-bearing application.

A Computational Fluid Dynamics model (CFD), including calculation of electric currents, thermal energy, fluid dynamics, mass transport, and reaction kinetics, was implemented to 
further understand the experiments, and to extrapolate results to industrially relevant conditions. The computational model accurately describes the measurable values, such as external temperature and methane conversion (Fig. S2-S4).

Figure 3 shows experimental and computational data. The reactor can be divided into three sections. The first section at the inlet, yields a rapid increase in temperature between the copper socket and coated zone (Fig. 3A) as the entire heat supply is utilized for heating the process gas (Fig. 3B). In the second section, the coated zone, the temperature initially drops, as the endothermic reaction consumes more heat than supplied for the process (Fig. 3A). Hereafter, the temperature profile is close to linear, with a significantly smaller slope than in the first zone, as the endothermic reaction consumes large amounts of heat. In the third section, the outlet (Fig. $3 \mathrm{~A})$, the temperature increases again more rapidly, reaching a maximum of $800^{\circ} \mathrm{C}$, before dropping promptly to $100^{\circ} \mathrm{C}$. Near the end of the reactor, the copper sockets exchange heat with ambient conditions facilitating rapid cooling.

Fig. 3. Experimental results and model predictions at ambient pressure A) Axial temperature profile and methane conversion at $1700 \mathrm{Nml} / \mathrm{min}$. The equilibrium temperature is the temperature at which a given gas composition is in thermodynamic equilibrium with respect to the SMR reaction (eq. 1). B) CFD modelled thermal contours across reactor. C) Methane consumption rate for the innermost $50 \mu \mathrm{m}$ of the coat (out of $128 \mu \mathrm{m}$ ), evaluated near in- and outlet cf. Fig. 3A. D) Measured exit temperature against methane conversion for the resistanceheated reformer for different gas flows.

Due to the uniform supply of heat to the process, the near constant heat flux (Fig. S5) ensures the gas mixture is kept close to equilibrium throughout the entire catalytic length (Fig. 3A), opposed to what is observed for conventional reformers $(6,8)$. This results in better utilization of the reactor volume and limits detrimental side-reactions such as carbon formation (Fig. S6-S7). Radial thermal gradients (Fig. 3B) primarily arise from the convection in the reactor. Temperature difference across the coat does not exceed $2^{\circ} \mathrm{C}$ along the linear section of the temperature profile. There is no discernible temperature gradient across the reactor wall, a significant benefit compared 15 with a fired reformer where the temperature difference between the inner and outer wall of the tubular reactor can cause thermal stress, critical to mechanical strength and reactor lifetime (27). Although internal diffusion limits the utilization of the catalyst, as the reaction quickly approaches equilibrium across the coat (Fig. 3C), the average catalyst utilization is $20 \%$ at the conditions in Figure 3C, i.e., up to an order of magnitude higher than reported for heterogeneous 20 catalyst for $\operatorname{SMR}(6,28,29)$. Most effective utilization of the catalyst is near the inlet, as lower temperature generates lower reaction rates (Fig. S8-S9). At the outlet, equilibrium is reached within the innermost $50 \mu \mathrm{m}$ of coat, equivalent to $39 \%$ of the coat thickness. The improved catalyst utilization is primarily due to the absence of thermal gradient in the catalyst. Further 
optimization of the catalyst utilization is feasible, as Figure $3 \mathrm{C}$ indicates that only $40-50 \mu \mathrm{m}$ of a uniform coat is required for full conversion, increasing catalyst utilization up to $65 \%$. As the flow is always completely laminar in the given process design (Reynolds number $\ll 2100(30)$ ), radial mass transport occurs solely by molecular diffusion to the surface of the catalyst, resulting in an external mass transport limitation (bulk-to-surface), correlated to the gas velocity (Fig. S10). The external diffusion limit can be seen by the increased temperature required to reach equivalent conversion as the flow rate increases (Fig. 3D). Higher conversion may be achieved by increasing the reactor temperature, at the expense of increasing the temperature difference relative to equilibrium (Fig. 3D). As the process gas approaches full conversion, a vertical asymptote is observed due to increasing kinetic hindrance of the reaction. The vertical asymptote occurs at lower conversion for higher flow rates, thus limiting maximum conversion achievable without altering geometry or operational conditions, such as pressure or steam-to-carbon ratio. For reference, an industrial SMR rarely operates above $90 \%$ conversion of methane. A significant benefit of the resistance-heated design is the possibility for exceptionally compact reactors (23). If we use the model developed in this work, for a single tube and extrapolate it to several parallel reformer tubes matching the capacity of an SMR, we find that a conventional $1100 \mathrm{~m}^{3}$ side-fired reformer producing $2230 \mathrm{kmol} \mathrm{H}_{2} / \mathrm{h}$ can be replaced with a ca. $5 \mathrm{~m}^{3}$ resistance-heated reformer (Fig. 4). Operating at similar conditions, the resistance-heated reformer has no risk of carbon deposition (Fig. S11). The substantial volume reduction obtained for the resistance-heated reformer is achievable as integration of the heat source makes the furnace obsolete, thus removing a significant portion of the reactor volume. Further volume reduction is envisioned if the geometry or operation conditions are optimized, however this is not 
pursued at this point. It should be noted that additional combustion air blowers, waste heat section, among others for the SMR are not included, while wiring and power supply for the resistance-heated reformer are omitted in this comparison.

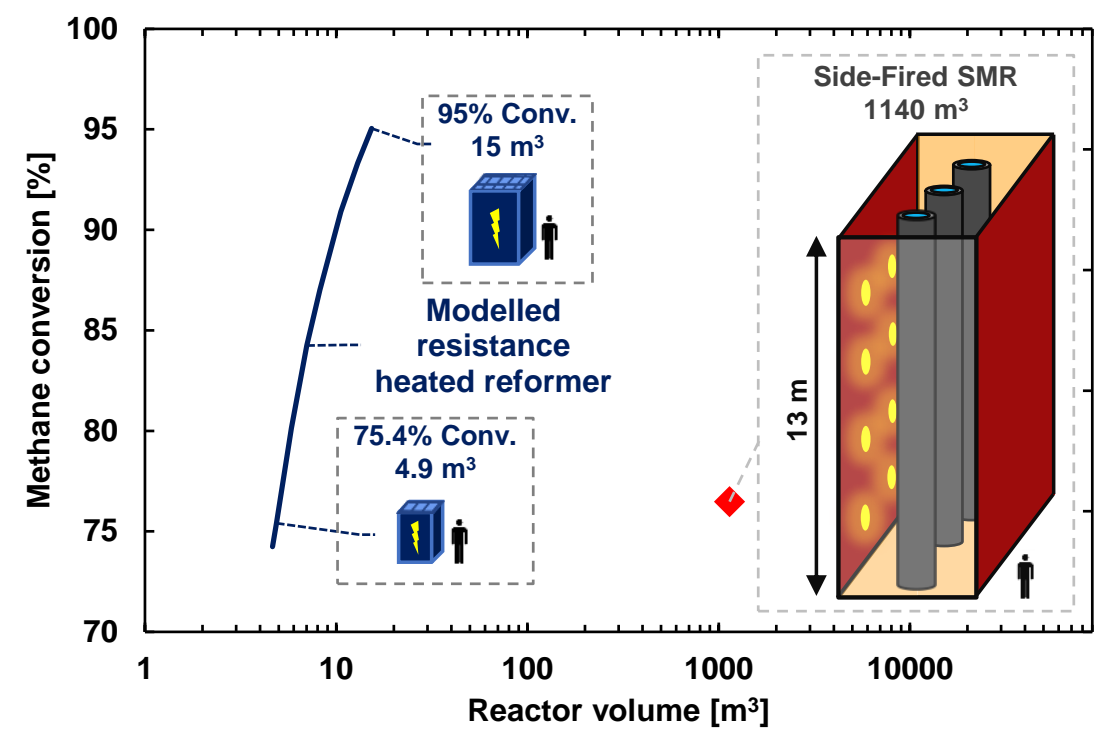

Fig. 4. Scaling opportunities for industrial production. Modelled methane conversion for a resistance-heated reformer scaled to a capacity of $2230 \mathrm{kmol} \mathrm{H} / \mathrm{h}$, compared with a side-fired SMR operating at $75.4 \%$ methane conversion. The comparison is done at industrial operating conditions, $T_{\text {in }}=466^{\circ} \mathrm{C}, T_{\text {out }}=920^{\circ} \mathrm{C}, \mathrm{S} / \mathrm{C}=1.8, P_{\text {out }}=26.7 \mathrm{barg}$. The model is limited to a $20^{\circ} \mathrm{C}$ difference from the equilibrium temperature (26). The electrification, uniform heating, and potential for exceptionally compact reactors present a disruptive approach to resolve the $\mathrm{CO}_{2}$ emission issues and current constraints regarding design, operation, and process integration for hydrogen production by SMR. Besides reducing $\mathrm{CO}_{2}$ emissions, implementation of the resistance-heated reactor into existing plants could offer alternative operation conditions, reducing the steam-to-carbon ratio, or operate at increased methane conversion, typically limited by carbon deposition and temperatures (ie. material constraints). High methane conversion coupled with an alternative purification technology could 
even provide a local source of $\mathrm{CO}_{2}$ for other processes. With less need for heat-recovery, resistance-heated reforming is efficiently applicable at many different sizes, promoting delocalization designs by utilizing the existing and well-developed infrastructure of natural gas, or potentially also biogas. Low thermal mass can also lead to reformers optimized for intermittent operation, following the fluctuations in availability of excess renewable energy with possible startup times in seconds $(23,26)$. The operating costs for an electrified reformer are directly related to the cost of electricity, natural gas, and $\mathrm{CO}_{2}$ taxes. Preliminary estimates indicate that a resistance-heated reformer would be on par with current fired reformers in regions with a high production of renewable electricity. This work illustrates the disruptive opportunities achievable by electrification of fundamental industrial processes. With the swiftly decreasing cost of electricity from renewable sources, resistive heating is an environmental, and economically appealing, solution for providing the necessary heat for strongly endothermic industrial processes, on the path towards a more sustainable society. 


\section{References and notes:}

1. L. Barreto, A. Makihira, K. Riahi, Int. J. Hydrogen Energy. 28, 267-284 (2003).

2. International Energy Agency (IEA), $\mathrm{CO}_{2}$ capture and storage. A key abatement option (OECD, 2008).

3. P. L. Spath, M. K. Mann, National Renewable Energy Laboratory (NREL), TP-57027637, (2001).

4. D. Bonaquist, $A$ white paper, Praxair.com, (2010).

5. D. A. Latham, K. B. McAuley, B. A. Peppley, T. M. Raybold, Fuel Process. Technol. 92 , 1574-1586 (2011).

6. J. Rostrup-Nielsen, L. J. Christiansen, Concepts in Syngas Manufacture (Imperial College Press, 2011).

7. J. R. Rostrup-Nielsen, Catal. Today. 145, 72-75 (2009).

8. A. Kumar, M. Baldea, T. F. Edgar, Comput. Chem. Eng. 105, 224-236 (2017).

9. I. Chorkendorff, J. W. Niemantsverdriet, Concepts of Modern Catalysis and Kinetics (Wiley, 2nd Revisi., 2007).

10. G. D. Wehinger et al., AlChe J. 62, 4436-4452 (2016).

11. M. Behnam, A. G. Dixon, Int. J. Chem. React. Eng. 15, 1-17 (2017).

12. J. Sehested, Catal. Today. 111, 103-110 (2006).

13. Y. Hiramitsu, M. Demura, Y. Xu, M. Yoshida, T. Hirano, Appl. Catal. A Gen. 507, 162168 (2015).

14. K. Johnsen, H. J. Ryu, J. R. Grace, C. J. Lim, Chem. Eng. Sci. 61, 1195-1202 (2006).

15. S. A. Wassie et al., Int. J. Hydrogen Energy. 42, 14367-14379 (2017).

16. L. C. Buelens, V. V Galvita, H. Poelman, C. Detavernier, G. B. Marin, Science. 354, 449452 (2016).

17. R. Ma, B. Castro-Dominguez, I. P. Mardilovich, A. G. Dixon, Y. H. Ma, Chem. Eng. J. 303, 302-313 (2016).

18. A. Y. Tonkovich et al., Chem. Eng. Sci. 59, 4819-4824 (2004).

19. A. Karim, J. Bravo, D. Gorm, T. Conant, A. Datye, Catal. Today. 110, 86-91 (2005).

20. L. Wang, Y. Yi, C. Wu, H. Guo, X. Tu, Angew. Chemie - Int. Ed. 56, 13679-13683 (2017).

21. M. G. Vinum et al., Angew. Chemie - Int. Ed. 57, 10569-10573 (2018). 
22. M. Rieks, R. Bellinghausen, N. Kockmann, L. Mleczko, Int. J. Hydrogen Energy. 40, 15940-15951 (2015).

23. L. Zhou, Y. Guo, M. Yagi, M. Sakurai, H. Kameyama, Int. J. Hydrogen Energy. 34, 844858 (2009).

24. A. L. Jongerius, P. C. A. Bruijnincx, B. M. Weckhuysen, Green Chem, 3049-3056 (2013).

25. M. Balakrishnan, E. R. Sacia, A. T. Bell, ChemSusChem, 2796-2800 (2014).

26. Materials and methods are available in the supplementary information.

27. K. Aasberg-Petersen et al., Appl. Catal. A Gen. 221, 379-387 (2001).

28. J. Xu, G. F. Froment, AIChE J. 35, 97-103 (1989).

29. M. V. Twigg, D. E. Ridler, in Catalyst Handbook, M. V. Twigg, Ed. (Second Edi., 1996), pp. 225-282.

30. R. B. Bird, W. E. Stewart, E. N. Lightfoot, Transport Phenomena (Wiley, ed. 2nd, 2002).

Acknowledgments: Funding: This work was supported by Innovation Fund Denmark (IFD) under File No.5160-00004B and research grant (9455) from VILLUM FONDEN. Author contributions: All authors contributed substantially to this work. Competing interest: There are no conflict of interest to declare. Data and materials availability: All data are available in the main text or the supplementary materials.

\section{Supplementary Materials:}

Materials and Methods

Supplementary text

Figures S1-S12

Table S1

References (31-40) 